\title{
Unifocal Ventricular Premature Complex by ECG Finding
}

National Cancer Institute

\section{Source}

National Cancer Institute. Unifocal Ventricular Premature Complex by ECG Finding. NCI Thesaurus. Code C102725.

An electrocardiographic finding of premature ventricular complexes which have a single distinct morphology, suggesting origin at one ventricular site. 